\title{
Why Run a Million Regressions? Endogenous Policy and Cross-Country Growth Empirics
}

\author{
Günther Rehme* \\ Technische Universität Darmstadt ${ }^{\dagger}$
}

January 15, 2002

\begin{abstract}
This paper analyses the link between growth and public policy when the latter depends on economically important fundamentals. When policy is endogenous the measured effects of policy on growth will generally be biased. Using a widely quoted theoretical model, the signs of the biases are derived. It is shown that the usually reported effects on growth of tax rate variables related to GDP, the ratio of public investment to total investment and the ratio of redistributive transfers to GDP are generally biased downwards. Based on these signed biases the paper discusses some empirical results that seem puzzling from a theoretical viewpoint.
\end{abstract}

Keywords: Growth, Public Policy, Cross-Sectional Models

JEL classification: O4, C2

*This paper is based on research that I have conducted at the European University Institute. I would like to thank Tony Atkinson, James Mirrlees, Robert Waldmann and Robert K. von Weizsäcker for helpful advice and useful suggestions. Of course, all errors are my own. Financial support by the Deutscher Akademischer Austauschdienst (DAAD), grant no. 522-012-516-3, is gratefully acknowledged.

$\dagger$ Correspondence: TU Darmstadt, FB 1/VWL 1, Schloss, D-64283 Darmstadt, Germany. phone: +49-6151-162219 ; fax: +49-6151-165553; E-mail: rehme@hrzpub.tu-darmstadt.de 


\section{Introduction}

This paper analyzes empirical findings that appear to be at odds with theoretical predictions as regards the effects of policy on growth.

In this context, almost all researchers acknowledge that their empirical work may be riddled by endogeneity problems. This paper concentrates on exactly these problems. More precisely, it attributes the discrepancy of results to the fact that policy is economically endogenous and that treating it as exogenous provides one with a misleading picture of the relationship between fiscal policy and growth.

For instance, many authors have investigated the effects of taxation on longrun growth. Although employing similar (theoretical) frameworks, their conclusions differ widely. See, for example, King and Rebelo (1990), Lucas (1990), Rebelo (1991), Jones, Manuelli and Rossi (1993), Pecorino (1993), (1994), or Stokey and Rebelo (1995).

The impact of productive government spending has, for instance, been analyzed by Aschauer (1989), Barro (1990) or Barro and Sala-i-Martin (1992). According to their theoretical results productive government spending should play a significant role in influencing the private return on capital and through that the long-run growth rate.

The link between (re-)distribution and growth has e.g. been analyzed by Bertola (1993), Alesina and Rodrik (1994), Persson and Tabellini (1994), or Perotti (1996). These studies often find that theoretically redistribution of resources from the accumulated towards the non-accumulated factor of production should be expected to affect growth negatively.

To test these theoretical predictions a large number of contributions has pro- 
ceeded by taking averages of their data over time and run simple cross-country OLS regressions over these averages. ${ }^{1}$ For that reason the paper concentrates on simple statistics based on time averages of variables, bearing in mind that simple statistics may also be relevant for more sophisticated methods.

For instance, Koester and Kormendi (1989), Barro (1991), (1997), Levine and Renelt (1992), Easterly and Rebelo (1993a), or Sala-i-Martin (1997) have analyzed the effects of fiscal policy on growth. Most of them find that tax rates or other, tax financed fiscal variables have a negative, but - when controlling for initial income - insignificant effect on growth. That would cast doubt on Barro (1990) or Barro and Sala-i-Martin (1992) who show that some of these variables should have a significant and (often) positive effect.

In this paper it is assumed that public policy takes account of fundamental economic variables that may or may not be included in growth regressions. The assumption of endogenous policy implies that the OLS estimates of the effect of public policy variables on growth are generally biased, implying that correct statistical inferences would not really be possible.

Based on a simplified version of the widely quoted model of Alesina and Rodrik (1994), theoretical correlations between public policy and fundamental economic variables are derived to sign the biases. That, in turn, allows for interpretations of some empirical findings that seem puzzling from a theoretical viewpoint.

The theory would predict that the estimates for the effects on growth of tax rate variables related to the tax base are generally biased upwards and so over-

\footnotetext{
${ }^{1}$ In the paper 'simple cross-country OLS regression' is meant to reflect that procedure of handling the time series dimension of the data. Of course, 'simple' does not mean simplistic, since the availability of data may not allow for another or a 'better' method of analysis. More recently some authors have advocated the use of dynamic panel data methods to pay explicit attention to the time series dimension. See e.g. Caselli, Esquivel and Lefort (1996). But the latter methods seem to have their own problems as e.g. argued by Barro (1997), p. 37, Temple (1999), p. 132, and e.g. analyzed by Banerjee, Marcellino and Osbat (2000).
} 
estimated. Thus, any reported negative effect of taxes on growth is understated, if measured by these variables. ${ }^{2}$

However, in the macroeconomics literature tax rates are usually measured by variables related to GDP. ${ }^{3}$ It is shown that the estimates of the effect on growth of tax rate variables related to GDP are generally biased downwards. Thus, any reported negative (positive) effect of tax rates on growth would be overstated (understated), if measured by those variables. The systematic underestimation implies that the theoretical prediction that high tax rates negatively affect growth may be inherently untestable. Hence, it matters what variables one uses for tax rates in growth regressions.

If public policy is assumed to be exogenous, the estimated coefficients of the effect on growth of the ratio of productive public expenditure to total investment or to GDP are biased downwards under all polices considered. If public policy is assumed to be endogenous, the point estimates of the effect on growth of the ratio of public investment to total investment are biased downwards.

That has interesting implications for any hypothesis that claims that the breakdown of total investment between public and private investment does not materially affect growth. It also casts doubt on the hypothesis that a typical country comes close to the quantity of public investment that maximizes growth.

Under the assumption of endogenous policy, the estimated coefficients of the effect on growth of the ratio of redistributive transfers to GDP are generically biased downwards. That renders the hypothesis that redistribution is bad for growth untestable for the following reason: The prediction of the theoretical

\footnotetext{
${ }^{2}$ Effect is not meant to be causal. In this paper effect means that some underlying economic fundamental influences policy which in turn bears on growth. Then the 'true' effect of policy on growth is spurious really, but can only be picked up by the simple coefficients available.

${ }^{3}$ Common variables are 'the ratio of tax revenues to GDP' for average tax rates, or 'the ratio of the change in tax revenues to the change in GDP' for marginal tax rates.
} 
model is that redistributive transfers are bad for growth. However, in the model an increase in efficiency makes an optimizing, redistributing government grant less transfers to the non-accumulated factor of production. This last effect is ignored in cross-country growth regressions when one assumes that public policy is exogenous.

For theoretical reasons many researchers expect a negative coefficient for the effect of redistributive transfers on growth. However, many people find positive coefficients (for example, for the effect of social security contributions on growth, see Sala-i-Martin (1996)). As any downward bias of the estimated coefficients may be as large as minus infinity, a reported negative coefficient cannot corroborate the hypothesis that redistribution is bad for growth. On the other hand, any downward bias is perfectly consistent with many empirical findings and the alternative hypothesis that redistribution is not bad for growth.

The main insight of the paper's analysis is that the disentanglement of the interplay of economic fundamentals and policy one the one hand and policy and growth on the other is difficult and should provide an interesting area for further research.

The paper is organized as follows: Section 2 presents the theoretical model and analyzes endogenous policy. The next section uses theoretical correlations derived from the model to analyze the effect of tax, public investment and redistributive transfer variables on growth. Section 4 provides concluding remarks.

\section{Theory}

Consider a private ownership economy that is populated by two types of pricetaking, infinitely lived individuals who are all equally patient. One group of 
agents, the capitalists $(k)$, owns wealth equally and does not work. The other group of agents, the workers $(W)$, owns (raw) labour equally, but no capital. ${ }^{4}$ Population is stationary and each group of agents derives logarithmic utility from the consumption of a homogeneous, malleable good. Aggregate output is produced according to

$$
Y_{t}=A K_{t}^{\alpha} G_{t}^{1-\alpha} L_{t}^{1-\alpha} \quad, \quad 0<\alpha<1
$$

where $Y_{t}$ denotes aggregate output, $K_{t}$ is the real capital stock, $L_{t}$ is labour supplied, and $G_{t}$ are public inputs to production. See Barro (1990). Capital is broadly defined and includes human capital. ${ }^{5}$ The index $A$ reflects the economy's state of technology. It depends on cultural, institutional and technological development and captures long-run exogenous factors that play a role in the production process. Labour is inelastically supplied and normalized so that the total labour endowment equals unity, $L_{t}=1$. The model abstracts from the depreciation of capital so that output and factor returns are really defined in net terms.

The government taxes wealth at the constant rate $\tau$, redistributes a constant share $\lambda$ of its tax revenues to the workers ${ }^{6}$ and runs a balanced budget: $\tau K_{t}=G_{t}+\lambda \tau K_{t}$. The LHS depicts the tax revenues and the RHS public expenditures. The workers receive $\lambda \tau K_{t}$ as transfers and $G_{t}$ is spent on public inputs to production.

\footnotetext{
${ }^{4}$ The assumption may be justified by various arguments, especially for the long run. See e.g. Kaldor (1956), Pasinetti (1962), Schlicht (1975), Bourguignon (1981), or Bertola (1993).

${ }^{5}$ This eliminates a separate treatment of how human capital is accumulated. By assumption the economies are perfectly competitive and the return on human capital services equals that of physical capital services. See Mankiw, Romer and Weil (1992).

${ }^{6}$ Following Alesina and Rodrik (1994) the wealth tax scheme represents a broad class of distributive tax arrangements, which distort the investors' incentive to accumulate. These authors show that the optimal policies are constant over time and, thus, time-consistent. For convenience constancy of policy is assumed from the beginning in this paper.
} 
There are many identical, profit-maximizing firms which operate in a perfectly competitive environment. They are owned by the capital owners who rent capital to and demand shares of the firms. The shares are collateralized one-to-one by capital. The markets for assets and capital are assumed to clear at each point in time. The firms take $G_{t}$ as given and rent capital and labour in spot markets in each period. The price of output $y_{t}$ serves as numéraire and is set it equal to one. Profit maximization entails that firms pay each factor of production its marginal product,

$$
\begin{gathered}
r=\alpha A[(1-\lambda) \tau]^{1-\alpha} \\
w_{t} \equiv \eta(\tau, \lambda) K_{t}=(1-\alpha) A[(1-\lambda) \tau]^{1-\alpha} K_{t} .
\end{gathered}
$$

Because of the productive role of government services policy has a bearing on the marginal products. The return on capital is constant over time while the wages grow with the capital stock. Notice that more redistribution lowers $r$ and $\eta$, while higher taxes raise them.

The workers derive utility from consuming their entire income. They do not invest and are not taxed. Their intertemporal welfare is given by

$$
\int_{0}^{\infty} \ln C_{t}^{W} e^{-\rho t} d t \text { where } C_{t}^{W}=\eta(\tau, \lambda) K_{t}+\lambda \tau K_{t} .
$$

The capitalists choose how much to consume or invest, and they have perfect foresight about the prices and tax rates, which they take as given. They maximize 
their intertemporal utility according to

$$
\begin{gathered}
\max _{C_{t}^{k}} \int_{0}^{\infty} \ln C_{t}^{k} e^{-\rho t} d t \\
\text { s.t. } \quad \dot{K}_{t}=(r-\tau) K_{t}-C_{t}^{k} \\
K(0)=\overline{K_{0}}, \quad K(\infty)=\text { free, }
\end{gathered}
$$

where equation (6) is the capitalists' dynamic budget constraint which depends on their after-tax income $(r-\tau) K_{t}$. In Appendix A it is shown that their consumption and wealth optimally grow at

$$
\gamma \equiv \frac{\dot{C}_{t}^{k}}{C_{t}^{k}}=\frac{\dot{K}_{t}}{K_{t}}=(r-\tau)-\rho
$$

which is increasing in the after-tax return on capital and constant over time.

Equilibrium. In steady state the economy is characterized by balanced growth at the rate $\gamma$, which is first increasing and then decreasing in $\tau$ for given $\lambda$. Growth is maxmized when $\tau=[\alpha(1-\alpha) A]^{\frac{1}{\alpha}} \equiv \hat{\tau}$ and $\lambda=0$. If taxes higher than $\hat{\tau}$ are levied, growth is traded off against redistribution when $\lambda>0$ and $\check{\tau}>\hat{\tau}$.

Furthermore, $r-\tau=\tau\left(\alpha A[(1-\lambda) \tau]^{-\alpha}-1\right)$ so that for given policy an increase in efficiency $A$ or in the share of capital $\alpha$ raises growth.

Policy. The intertemporal welfare of an entirely pro-capital, $V^{r}$, resp. entirely pro-labour government, $V^{l}$, is given by

$$
V^{r}\left(C_{t}^{k}\right)=\frac{\ln \left(\rho K_{0}\right)}{\rho}+\frac{\gamma}{\rho^{2}} \quad \text { and } \quad V^{l}\left(C_{t}^{W}\right)=\frac{\ln \left[(\eta(\tau, \lambda)+\lambda \tau) K_{0}\right]}{\rho}+\frac{\gamma}{\rho^{2}}
$$


See Appendix B. The governments respect the right of private property and maximize the welfare of their clientele under the condition $\lambda \geq 0$.

The optimal pro-labour policy is derived in Appendix $\mathrm{C}$ and is given by

If $\rho \geq[(1-\alpha) A]^{\frac{1}{\alpha}} \quad$ then:

$$
\tau=\rho, \quad \lambda=1-\frac{[(1-\alpha) A]^{\frac{1}{\alpha}}}{\rho} .
$$

If $\rho<[(1-\alpha) A]^{\frac{1}{\alpha}}$ then:

$$
\tau\left[1-\alpha(1-\alpha) A \tau^{-\alpha}\right]=\rho(1-\alpha), \quad \lambda=0 .
$$

Denote the optimal pro-labour tax rate by $\check{\tau}$ and notice that for a wide range of parameter values there is no redistribution so that the model distinguishes between redistributing and non-redistributing governments.

In contrast, the pro-capital government chooses $\tau=\hat{\tau}$, does not redistribute and acts growth maximizing in this model by granting the maximum after-tax return on capital to the capital owners.

All optimal policies depend on $A, \alpha$, and $\rho$. Thus, policy is endogenous in the paper. The rate of time preference will not be considered any further because it is mostly considered a soft variable, which is very hard to measure. For the other variables I find the following 
Table 1: Growth and Policy Effects

\begin{tabular}{|c|c|c|c|c|c|c|c|}
\hline & \multicolumn{2}{|c|}{$\mathrm{PC}$} & \multicolumn{2}{|c|}{$\mathrm{PL}_{\lambda=0}$} & \multicolumn{3}{|c|}{$\mathrm{PL}_{\lambda \geq 0}$} \\
\hline & $\hat{\tau}$ & $\hat{\gamma}$ & $\check{\tau}$ & $\check{\gamma}$ & $\check{\tau}$ & $\lambda$ & $\check{\gamma}$ \\
\hline$A$ & + & + & + & + & 0 & - & + \\
\hline$\alpha$ & $?$ & + & $?$ & + & 0 & $?$ & + \\
\hline
\end{tabular}

PC - pro-capital, PL - pro-labour

Sign: (+) - positive, (-) - negative, (?) - ambiguous

See Appendix D. Thus, an increase in efficiency raises growth, does not imply lower tax rates but calls for lower redistribution under all policies considered. This is due to the externality of public inputs. Higher growth requires more tax revenues for productive services channelled into production in order to raise the return on capital and so growth.

In turn, a higher share of capital also raises growth under all policies, but that effect is ambiguous as regards taxes and redistribution. This is interesting because it means that shifting relatively more factor income towards capital may call for higher or lower taxes in order to generate a higher after-tax income for capital and higher growth. For instance, Alesina and Rodrik (1994), ftn. 7, cite theoretical support for the prediction that an increase in $\alpha$ raises redistributive pressure leading to higher taxes. Thus, higher taxes may even be optimal for a government that is only concerned about the welfare of the owners of the accumulated factor of production. 


\section{Growth Empirics}

According to the theory the empirical, long-run relationship between growth and policy for a country $i$ is of the form

$$
\gamma_{i}=f\left(\tau_{i}\left(\alpha_{i}, A_{i}\right), \lambda_{i}\left(\alpha_{i}, A_{i}\right), \alpha_{i}, A_{i}\right)=f\left(\alpha_{i}, A_{i}\right)
$$

where $f(\cdot)$ is a non-linear function of $\alpha_{i}$ and $A_{i}$ which are assumed to be countryspecific, that is, independent and thus uncorrelated across countries. ${ }^{7}$

An analysis of exogenous, once-and-for-all changes in $A_{i}$ is similar in spirit to models with exogenous technological change, which is commonly thought to be unobservable. ${ }^{8}$ Clearly, countries differ widely in the level of development, but reliable data and concepts capturing the essence of development are not readily available. Thus, $A_{i}$ is taken to be unobservable, implying that information on $A_{i}$ would be contained in the disturbance term and would not feature separately in the regressions. Then the second-best, but operationally viable model would be

$$
\gamma_{i}=\beta_{0}+\beta_{1} \alpha_{i}+\beta_{2} \tau_{i}\left(\alpha_{i}, A_{i}\right)+\beta_{3} \lambda_{i}\left(\alpha_{i}, A_{i}\right)+v_{i}
$$

where $v_{i}=v_{i}\left(A_{i}, \epsilon_{i}\right)$ is a country-specific disturbance term which depends on $A_{i}$ and $\epsilon_{i}$. The latter is assumed to be uncorrelated with $A_{i}$ as well as with each of the regressors, and $E\left(\epsilon_{i}\right)=0$.

\footnotetext{
${ }^{7}$ Under the assumption of exogenous policy $\gamma_{i}=g\left(\tau_{i}, \lambda_{i}, \alpha_{i}, A_{i}\right)$ where $\tau_{i}$ and $\lambda_{i}$ are independent of the other variables included in $g(\cdot)$. Notice that $f(\cdot)$ and $g(\cdot)$ may be observationally equivalent when particular combinations of $\alpha_{i}$ and $A_{i}$ lead to the same growth rate under either assumption. Thus, assume that empirical and theoretical researchers agree that the Data Generating Mechanism (DGP) is given by the joint probability distribution $D(\gamma, \tau, \lambda, \alpha, A)$, which is expressed in terms of steady state variables and, thus, ignores any time dependence. That reflects the procedure to take time-averages of data which are considered of interest.

${ }^{8}$ The discussion about the Solow-Residual reflects these difficulties. See, for instance, Barro and Sala-i-Martin (1995), chpt. 10.4.
} 
If that model were estimated by OLS, multicollinearity and the omission of a relevant variable would be a problem. As the error term correlates with the regressors or any transformation thereof depending on $\alpha$ or $A$, the conditions of weak exogeneity in the sense of Engle, Hendry and Richard (1983) are violated. ${ }^{9}$

A standard justification for treating policy as exogenous is a randomization argument. For example, Barro (1989a) argues that in a large sample public policies may be treated as randomly generated. That comes close to saying that policies are exogenous. But in light of this paper's analysis the argument would not hold. Even if all countries had different governments with different welfare functions so that polices looked randomly chosen, the model predicts that all policies would be influenced by fundamental economic variables included or not included in the regressions. The paper concentrates on exactly that problem.

Taxes. Most studies investigating the relation between taxes and growth use

$$
a v_{1}=\frac{T A R}{T A B}, \quad m_{1}=\frac{d T A R}{d T A B}, \quad a v_{2}=\frac{T A R}{G D P}, \quad m_{2}=\frac{d T A R}{d G D P}
$$

as regressor variables where $T A R$ denotes the total tax revenues in a country, and $T A B$ denotes the tax base. Usually, $a v_{1}$ and $a v_{2}$ represent average tax rates, whereas $m_{1}$ and $m_{2}$ are often used as proxies for marginal tax rates. ${ }^{10}$

From the model $\tau$ is equal to both $a v_{1}$ and $m_{1}$, which are related to the tax base. ${ }^{11}$ Suppose $\gamma_{i}=\delta_{0}^{1}+\delta_{1}^{1} \tau_{i}+u_{i}^{1}$ is run and it is assumed that policy is

\footnotetext{
${ }^{9}$ Thus, reported $t$-statistics will not report the true significance levels and statistical inferences are not really possible. However, here the focus is on the problem caused by assuming that policy is exogenous.

${ }^{10}$ All these variables are problematic representations for aggregate relationships between fiscal policy and growth. For instance, the 'marginal tax rate' $m_{2}$ is commonly obtained by regressing tax revenues on GDP, where the resulting regression coefficient is interpreted as the 'marginal tax rate'. See, for instance, Koester and Kormendi (1989) or Easterly and Rebelo (1993b). That raises the question whether GDP really is the relevant tax base.

${ }^{11}$ The equality appears problematic as one would often expect that marginal tax rates $(m)$ are
} 
exogenous. In that case the OLS estimator of $\delta_{1}^{1}$, call it $d_{1}^{1}$, would be unbiased. ${ }^{12}$ However, assuming that policy is exogenous when in fact it is endogenous yields biased estimates, because $d_{1}^{1}=\frac{\sum_{i}\left(\tau_{i}-\bar{\tau}\right) \gamma_{i}}{\sum_{i}\left(\tau_{i}-\bar{\tau}\right)^{2}}$ and substituting in the 'true' model (13) yields $d_{1}^{1}=\beta_{2}+\beta_{1} \sum_{i} c_{i} \alpha_{i}+\beta_{3} \sum_{i} c_{i} \lambda_{i}+\sum_{i} c_{i} v_{i}$ where $c_{i}=\frac{\left(\tau_{i}-\bar{\tau}\right)}{\sum_{i}\left(\tau_{i}-\bar{\tau}\right)^{2}}$ and $v_{i}=v_{i}\left(A_{i}, \epsilon_{i}\right)$. Taking expectations under the assumption that policy is in fact endogenous one obtains ${ }^{13}$

$$
E\left(d_{1}^{1}\right)=\beta_{2}+\beta_{1} E\left[\sum_{i} c_{i} \alpha_{i}\right]+\beta_{3} E\left[\sum_{i} c_{i} \lambda_{i}\right]+E\left[\sum_{i} c_{i} v_{i}\right]
$$

Hence, $d_{1}^{1}$ is generally biased because the sum of the expectations of the expressions on the RHS is non-zero.

The bias is due to three factors. First, the expression $\sum_{i} c_{i} v_{i}$ is positive for all non-redistributing governments since $\operatorname{cov}\left(\tau_{i}, A_{i}\right)>0$ from Table 1 . Second, $\operatorname{cov}\left(\tau_{i}, \lambda_{i}\right) \geq 0$, which is positive if governments redistribute. Third, if $\operatorname{cov}\left(\tau_{i}, \alpha_{i}\right) \geq 0$, the bias is clearly positive.

Proposition 1 Let $a v_{1}$ or $m_{1}$ have the same properties as $\tau$. Simple crosscountry OLS regressions of the growth rate on $\tau$, av $v_{1}$ or $m_{1}$ assuming that policy is exogenous, when in fact it is endogenous, yields generically biased estimates. In many cases and definitely if $\operatorname{cov}(\tau, \alpha) \geq 0$, the bias would be positive.

Thus, the coefficients measuring the effect of these variables on growth are overestimated so that either any reported negative effect is understated or any

not lower and often higher than average tax rates $(a v)$. One should bear in mind, however, that for economies with flat-rate tax systems, which are often analyzed and sometimes advocated to be adopted in the theoretical literature, $a v=m$ would certainly hold. Thus, a discussion of the effect of such tax variables on growth in simple OLS cross-country growth regressions may be worth for that and for theoretical reasons.

${ }^{12}$ The superscript 1 indicates that the regression is run on variables related to the tax base.

${ }^{13}$ Under exogenous policy the expectation would be conditional on $\left(\tau_{i}, \lambda_{i}, A_{i}, \alpha_{i}\right)$, since all researchers agree on the 'true' DGP by assumption. Under endogenous policy the expectation is only conditional on $\left(A_{i}, \alpha_{i}\right)$, of course. 
reported positive effect is overstated. In the theoretical literature higher taxes are usually shown to affect growth negatively. Hence, if one found a negative effect for regressors like $\tau$, $a v_{1}$ or $m_{1}$ one could be 'sure' that the effect is indeed negative. Even a reported positive effect would not invalidate the prediction that the 'true' effect is really negative. Hence, Proposition 1 provides a negative result for hypothesis testing, but it offers an important 'positive' link to empirical research in that it provides an argument that any theoretically derived negative relationship between taxes and growth is 'true', if the regressors are $\tau$, av $v_{1}$ or $m_{1}$ and have the theoretical model's properties.

However, Proposition 1 rests on strong assumptions. The determination of a country's tax base most relvant for growth is extremely difficult. Usually governments raise all sorts of taxes on different tax bases. Furthermore, countries do not necessarily use the same tax bases and for some tax bases data are difficult to obtain. For that reason the vast majority of cross-country growth studies use $a v_{2}$ or $m_{2}$ as regressors.

But the choice of regressors may affect the underlying structure of the estimated and the statistical model. Going from $\tau$ or $a v_{2}$ to $m_{2}$ often entails a non-linear reparametrization of an original estimated model or a different model altogether. ${ }^{14}$ For instance, the choice of $a v_{2}$ as a regressor variable means that $\gamma=f^{2}\left(\frac{\tau K_{t}}{Y_{t}}, \alpha_{i}, A_{i}, \rho_{i}\right)=f^{2}\left(\alpha_{i}, A_{i}, \rho_{i}\right)$ which is usually not the same as $f(\cdot)$ in (12). Instead of trying to find a reparametrization of the original model assume all policy variables react to the fundamental variables as in Table 1 and $f^{2}\left(a v_{2}, \cdot\right)$ can be linearized as $\gamma_{i}=\beta_{0}^{2}+\beta_{1}^{2} \alpha_{i}+\beta_{2}^{2} a v_{2 i}+v_{i}^{2}\left(A_{i}, \epsilon_{i}\right)$. The same assumptions

\footnotetext{
${ }^{14}$ It should be borne in mind that the theoretical model is supposed to capture essential properties of the relation between taxes and growth. Thus, it is perfectly valid and common scientific procedure to reduce a problem to a simple model and use some, but not necessarily the closest estimable and statistical models to test the theoretical predictions. On this point see, for instance, Spanos (1986), chpts. 1.2 and 26.
} 
and arguments apply for $m_{2}$ and $f^{2}\left(m_{2}, \cdot\right)$.

From the theoretical model it is not difficult to verify that ${ }^{15}$

$$
a v_{2} \equiv \frac{\tau K_{t}}{Y_{t}}=\frac{\tau^{\alpha}}{A(1-\lambda)^{1-\alpha}} \quad \text { and } \quad m_{2} \equiv \frac{d\left(\tau K_{t}\right)}{d Y_{t}}=\frac{a v_{2}}{1-\alpha}
$$

Thus, $m_{2}>a v_{2}$ which is a property most researcher would expect. For instance, Koester and Kormendi (1989), p. 370/1, find that marginal tax rates $m_{2}$ are significantly different from average tax rates $a v_{2}$ and that 'across countries marginal tax rates average about one-and-one-half to two times average tax rates'.

Notice that even under the assumption of exogenous policy the coefficients on $a v_{2}$ and $m_{2}$ would be biased downwards. If policy is endogenous, then $a v_{2}(\hat{\tau})=$ $\alpha(1-\alpha), m_{2}(\hat{\tau})=\alpha$ and so $\frac{d a v_{2}(\hat{\tau})}{d A}=\frac{d m_{2}(\hat{\tau})}{d A}=0$. For non-redistributing policies $\frac{d a v_{2}}{d A}=\frac{\tau^{\alpha}}{A^{2}}\left[\frac{\alpha A}{\tau} \frac{d \tau}{d A}-1\right]$ and $\frac{d m_{2}}{d A}=\left(\frac{1}{1-\alpha}\right) \frac{d a v_{2}}{d A}$. Furthermore, $\frac{\alpha A}{\tau} \frac{d \tau}{d A}<1$ if

$$
\begin{aligned}
\alpha^{2}(1-\alpha) A\left(\tau^{\alpha}-\alpha(1-\alpha)^{2} A\right)^{-1} & <1 \\
\alpha(1-\alpha)^{2} A+\alpha^{2}(1-\alpha) A & <\tau^{\alpha} \\
\hat{\tau} & <\tau
\end{aligned}
$$

which is true for $\check{\tau}>\hat{\tau}$. Thus, $\frac{\operatorname{dav}_{2}(\check{\tau})}{d A}$ and $\frac{d m_{2}(\check{\tau})}{d A}$ are negative. For a redistributing government $a v_{2}=\frac{\rho}{A[(1-\alpha) A]^{\frac{1-\alpha}{\alpha}}}$ which decreases in $A$. By a similar argument one verifies that $m_{2}$ decreases in $A$ under that policy. Hence, $\operatorname{cov}\left(a v_{2 i}, A_{i}\right)$ and $\operatorname{cov}\left(m_{2 i}, A_{i}\right)$ are non-positive.

To keep matters simple assume that the covariance of $a v_{2 i}\left(m_{2 i}\right)$ and $\alpha_{i}$ is non-positive. ${ }^{16}$ Then $a v_{2}$ co-varies with $A$ or $\alpha$ in the same way as $m_{2}$ does.

\footnotetext{
${ }^{15}$ Recall $Y_{t}=A K_{t}^{\alpha} G_{t}^{1-\alpha}$ and $G_{t}=(1-\lambda) \tau k_{t}$. Then $a v_{2}=\frac{\tau K_{t}}{Y_{t}}=\frac{\tau K_{t}}{A K_{t}^{\alpha}\left((1-\lambda) \tau K_{t}\right)^{1-\alpha}}$ which reduces to the expression in (14). Furthermore, $\frac{d Y_{t}}{d\left(\tau K_{t}\right)}=(1-\alpha) A K_{t}^{\alpha}(1-\lambda)^{1-\alpha}\left(\tau K_{t}\right)^{-\alpha}$. Taking the inverse yields $\frac{d \tau K_{t}}{d Y_{t}}=\frac{\tau^{\alpha}}{(1-\alpha) A(1-\lambda)^{1-\alpha}}=\frac{a v_{2}}{1-\alpha}$.

${ }^{16}$ For instance, for given tax policies of all non-redistributing governments an increase in $\alpha$
} 
Suppose one assumes exogenous policy, although it is not, and runs the regression $\gamma_{i}=\delta_{0}^{2}+\delta_{1}^{2} a v_{2 i}+u_{i}^{2}$ where the superscript 2 indicates that model $f^{2}(\cdot)$ is being analyzed. Proceeding as above reveals that $d_{1}^{2}$ is generically biased downwards, that is, it is biased down unless all governments act growth maximizing and $\operatorname{cov}\left(a v_{2 i}, \alpha_{i}\right)=0$. Hence, any measured negative effect of $a v_{2}$ on $\gamma$ may often be overstated. Similar arguments hold for $m_{2}$.

Proposition 2 Assume policy variables react to fundamental economic variables as in Table 1, the DGPs for $f(\cdot)$ and $f^{2}(\cdot)$ are the same, and $\operatorname{cov}\left(a v_{2 i}, \alpha_{i}\right)$ and $\operatorname{cov}\left(m_{2 i}, \alpha_{i}\right)$ are non-positive. A simple cross-country OLS regression of $\gamma$ on av $v_{2}$ or $m_{2}$ yields generically biased estimates. Unless all governments in the sample pursue growth maximizing polices, the estimates are biased downwards.

The downward bias may be explained as follows: Tax rates higher than the growth maximizing ones lead to relatively lower growth. That explains why many authors find a negative point estimate for $\delta_{1}^{2}$. For instance, Koester and Kormendi (1989) report $d_{1}^{1}=-0.074(-2.18)$ for a simple regression of growth on average tax rates. ${ }^{17}$ (All t-statistics are shown in parentheses.) However, in the model the bad direct effect of high taxes is compensated by the good effect of taxes channelled into production via public services. That good effect is larger when $A$ is higher and it is ignored when assuming that policy is exogenous.

For instance, Levine and Renelt (1992), Engen and Skinner (1992), or Sala-iMartin (1997) find that controlling for initial income $y_{0}$ renders their estimated effects of taxes on growth insignificant. However, putting initial income in the regression first and then adding a tax variable often renders the estimated coeffireduces $a v_{2}$. Thus, the results below are conditional on that or that $\operatorname{cov}\left(a v_{2 i}, A_{i}\right)\left(\operatorname{cov}\left(m_{2 i}, A_{i}\right)\right)$ is more important than $\operatorname{cov}\left(a v_{2 i}, \alpha_{i}\right)\left(\operatorname{cov}\left(m_{2 i}, \alpha_{i}\right)\right)$. The condition is testable and any results derived from it are therefore falsifiable.

${ }^{17}$ The reported coefficient on $m_{2}$ was $-0.025(-1.87)$. 
cient of the effect of initial income on growth insignificant. For instance, Easterly and Rebelo (1993a) find in their growth regressions that seven(!) out of thirteen tax variables render the estimated coefficients for the effect of initial income on growth insignificant. This possibility is often ignored, although it provides a rationale for not including either tax measures or initial income in growth regressions. Thus, from a statistical viewpoint alone there is no reason why authors such Levine and Renelt (1992) or Sala-i-Martin (1997) conclude that fiscal variables are mostly non-robust regressors when fiscal variables are highly correlated with initial income.

A downward bias of $d_{1}^{2}$ plays an important role in explaining why one is likely to obtain insignificant coefficients in a regression $\gamma_{i}=\xi_{0}^{2}+\xi_{1}^{2} a v_{2 i}++\xi_{2}^{2} y_{0 i}+w_{i}^{2}$. Elementary econometrics tells one that the OLS estimator of $\xi_{1}^{2}$ is given by

$$
\hat{\xi}_{1}^{2}=\frac{d_{1}^{2}-\hat{\xi}^{2}{ }_{13} \hat{\xi}^{2}{ }_{32}}{1-\hat{\xi}^{2}{ }_{23} \hat{\xi}^{2}{ }_{32}}
$$

where $d_{1}^{2}$ reflects the slope of the simple regression of $\gamma_{i}$ on $a v_{2}, \hat{\xi}^{2}{ }_{13}$ the slope of the regression of $\gamma_{i}$ on $y_{0 i}, \hat{\xi}^{2}{ }_{23}$ the slope of the regression of $a v_{2}$ on $y_{0 i}$ and $\hat{\xi}^{2}{ }_{32}$ the slope of the regression of $y_{0 i}$ on $a v_{2}$. E.g., Koester and Kormendi report

$$
\begin{array}{ll}
d_{1}^{2}=-0.074(-2.18) & , \quad \hat{\xi}_{13}^{2}=-0.053(-3.52), \\
\hat{\xi}_{23}^{2}=+0.293(+6.32) & , \quad \hat{\xi}_{1}^{2}=-0.005(-0.11)
\end{array}
$$

from which the imputed value of $\hat{\xi}_{32}^{2}$ is 1.3389 . It is instructive to see that including initial income reduces the point estimate for the effect of taxes on growth $\left(d_{1}^{2}\right.$ vs. $\left.\hat{\xi}_{1}^{2}\right)$ by a factor of 14.8 and makes it statistically insignificant. ${ }^{18}$

\footnotetext{
${ }^{18}$ Notice that taxes and initial income are positively and comparatively strongly correlated $\left(\hat{\xi}_{23}^{2}\right)$, indicating that Wagner's Law holds which asserts a positive relation between the size of the government and per capita income. Furthermore, initial income is negatively related to
} 
Suppose $\hat{\xi}_{13}^{2}, \hat{\xi}_{23}^{2}$ and $\hat{\xi}_{32}^{2}$ were unbiased estimates. By Proposition 2 any negative value of $d_{1}^{2}$ is overstated so that the true $\delta_{1}^{2}$ would be less negative than the value reported. If one fixes the other estimates one gets

$$
\hat{\xi}_{1}^{2}=\frac{d_{1}^{2}-(-0.053)(+1.3389)}{1-(+0.293)(+1.3389)}=\left(d_{1}^{2}+0.0710\right) \times 1.6455 .
$$

Underestimation means that a negative estimate $d_{1}^{2}$ would overstate any true (negative) $\delta_{1}^{2}$, which raises the problem of how big the bias is. Suppose $\delta_{1}^{2}=d_{1}^{2} \times x$ where $x \in(-\infty, 1)$ and that the unknown 'true' value is non-positive, $\delta_{1}^{2} \leq 0$.

Table 2: Bias Effects on $\hat{\xi}_{1}^{2}$ when $d_{1}^{2}=-0.074$

\begin{tabular}{|c|c|c|c|c|c|c|c|}
\hline$x$ & 0.99 & 0.95 & 0.9 & 0.85 & 0.80 & 0.5 & 0.10 \\
\hline$\hat{\xi}_{1}^{2}$ & -0.004 & +0.001 & +0.007 & +0.013 & +0.019 & +0.056 & +0.104 \\
\hline
\end{tabular}

Thus, a five-percent bias in $d_{1}^{2}$ raises $\hat{\xi}_{1}^{2}$ from -0.005 to +0.001 , that is, it pushes the point estimate of $\hat{\xi}_{1}^{2}$ towards zero. That is interesting, because many researchers control for initial income first and then add policy variables to their growth regressions. Most of them find that variables such as $a v_{2}$ take on values close to zero. Given the bias in $d_{1}^{2}$ the 'true' point estimate of $\hat{\xi}_{1}^{2}$ is likely to be positive and maybe statistically significant. Most authors argue that they find insignificant effects for variables such as $a v_{2}$ because of the high correlation between initial income and $a v_{2}$, that is, high $\hat{\xi}_{23}^{2}$ or $\hat{\xi}_{32}^{2}$.

However, a $\hat{\xi}_{1}^{2}$ which is close to zero may mean that the 'true' $\xi_{1}^{2}$ is positive and that biases in $d_{1}^{2}$ push $\hat{\xi}_{1}^{2}$ down towards zero. Hence, one cannot exclude the possibility that a higher 'ratio of tax revenues to GDP' may actually have a positive effect on growth.

By the same token one cannot exclude the possibility that marginal tax rates, growth, which is often interpreted as indicating conditional convergence in the growth process, that is, countries with lower initial income tend to have higher subsequent growth. 
measured by $m_{2}$, positively affect growth. For example, Perotti (1996) is puzzled to find positive and significant coefficients for the effect of marginal tax rates on growth in his 2SLS regressions.

A negative bias in the coefficients for $a v_{2}$ or $m_{2}$ implies that the theoretical prediction that higher taxes negatively affect growth is inherently untestable. Any reported value of the effect of tax variables such as $a v_{2}$ or $m_{2}$ on growth is always underestimated, that is, a reported negative effect would be overstated and a reported positive effect would be understated. As a reported negative effect may well be positive in 'reality' then, the theoretical prediction cannot be corroborated when using $a v_{2}$ or $m_{2}$ and the paper's theoretical model captures general properties of the effect of taxes and policy on growth.

Hence, it matters a great deal which tax variables one includes in growth regressions.

Public Investment. Sometimes growth is regressed on the ratio of government investment to GDP or total (private and public) investment to test how public investment such as changes in infrastructure affect growth. Theoretically, a significant and often positive relationship is expected. See, for instance, Aschauer (1989), Barro (1990), Barro and Sala-i-Martin (1992), or Barro and Sala-iMartin (1995), chpt. 4.4. Surprisingly, in many empirical studies such as Barro (1989b), (1991), or Barro and Sala-i-Martin (1995) chpt. 12.3 the effect of these variables on growth turns out to be statistically insignificant.

In this paper long-run total investment is given by $I_{t}=\gamma K_{t}$,

$$
\mathfrak{p} \equiv \frac{G_{t}}{Y_{t}}=\frac{1}{A}\left(\frac{G_{t}}{K_{t}}\right)^{\alpha}=\frac{((1-\lambda) \tau)^{\alpha}}{A} \text { and } \mathfrak{q} \equiv \frac{G_{t}}{\gamma K_{t}}=\frac{(1-\lambda) \tau}{\gamma}
$$

Barro (1991) uses public expenditure data to test his theoretical predictions 
which are based on $G_{t}$ arguing that it is a proxy for the change in the stock of public capital. That is a problematic assumption, possible implications of which he discusses. For consistency with empirical results, which are often based on that, assume that $G_{t}$ is indeed a good proxy for public investment, that is, a proxy for the change in the stock of public capital for which data are difficult to obtain. Furthermore, in line with the previous discussion on taxes and for simplicity assume that the correlation between these ratios and $\alpha_{i}$ is less important than that between the ratios and $A_{i}$. Thus, all results below are conditional on that assumption.

Interestingly, for given tax policies both $\mathfrak{p}$ and $\mathfrak{q}$ are decreasing in $A$ or $\alpha$. Thus, the coefficients measuring the effect of these variables on growth would be biased downwards even under the assumption of exogenous policy.

For endogenous policy the ratio of public investment to total investment $(\mathfrak{q})$ is discussed first. To this end let $b \equiv(1-\lambda) \tau$. Then $\frac{d b}{d A}=-\frac{d \lambda}{d A} \tau+\frac{d \tau}{d A}(1-\lambda)$ which is positive for all policies considered. I want to show that $\frac{d q}{d A}<0$.

$$
\operatorname{sgn}\left(\frac{d \mathfrak{q}}{d A}\right)=\frac{d b}{d A} \gamma-\frac{d \gamma}{d A} b=\frac{d b}{d A}(r-\tau-\rho)-\left(\frac{d r}{d A}-\frac{d \tau}{d A}\right) b=\mathfrak{q}_{1}+\mathfrak{q}_{2}
$$

where $\mathfrak{q}_{1} \equiv\left(\frac{d b}{d A} r-\frac{d r}{d A} b\right)$ and $\mathfrak{q}_{2} \equiv \frac{d b}{d A}(-\tau-\rho)+\frac{d \tau}{d A} b$. Clearly $\mathfrak{q}_{2}<0$, since

$$
\begin{aligned}
\mathfrak{q}_{2} & =\left(-\frac{d \lambda}{d A} \tau+\frac{d \tau}{d A}(1-\lambda)\right)(-\tau-\rho)+\frac{d \tau}{d A}(1-\lambda) \tau \\
& =\frac{d \lambda}{d A} \tau(\tau+\rho)-\frac{d \tau}{d A}(1-\lambda) \rho<0
\end{aligned}
$$

with $\frac{d \lambda}{d A} \leq 0$ and $\frac{d \tau}{d A} \geq 0$ and at least one of the derivatives being non-zero for all 
policies considered. For $\mathfrak{q}_{1}$ one obtains

$$
\begin{aligned}
\mathfrak{q}_{1}=\frac{d b}{d A} r-\left(r_{A}+r_{b} \frac{d b}{d A}\right) b & =\left(r-r_{b} b\right) \frac{d b}{d A}-r_{A} b \\
=\alpha^{2} A b^{1-\alpha} \frac{d b}{d A}-r_{A} b & =\alpha b^{1-\alpha}\left[\alpha A \frac{d b}{d A}-b\right]
\end{aligned}
$$

which is non-positive for all non-redistributing policies since for $\lambda=0$ one gets $\alpha A \frac{d \tau}{d A} \leq \tau$ as has been shown in (15). For a redistributing government $b=$ $[(1-\alpha) A]^{\frac{1}{\alpha}}$ and $\frac{d b}{d A}=\frac{b}{\alpha A}$ so that $\mathfrak{q}_{1}=0$. Hence, $\mathfrak{q}_{1}+\mathfrak{q}_{2}<0$ and so $\frac{d \mathfrak{q}}{d A}<0$.

The ratio of government investment to GDP is $\mathfrak{p}=\frac{b^{\alpha}}{A}$ so that

$$
\operatorname{sgn}\left(\frac{d \mathfrak{p}}{d A}\right)=\alpha A b^{\alpha-1} \frac{d b}{d A}-b^{\alpha}=b^{\alpha}\left[\frac{d b}{d A} \frac{\alpha A}{b}-1\right]
$$

which is zero for growth maximizing and redistributing policies. For non-redistributing policies it is negative.

Proposition 3 Assume policy variables react to fundamental economic variables as in Table 1, the DGP is the same as that for $f(\cdot)$ and $\gamma$ is regressed on $\mathfrak{q}$ or $\mathfrak{p}$. If $\operatorname{cov}\left(\mathfrak{q}_{i}, \alpha_{i}\right)$ and $\operatorname{cov}\left(\mathfrak{p}_{i}, \alpha_{i}\right)$ are non-positive, then in simple cross-country OLS regressions

1. the estimated coefficients measuring the effect of $\mathfrak{q}$ on growth are biased downwards under all policies considered.

2. the estimated coefficients measuring the effect of $\mathfrak{p}$ on growth are biased downwards if all governments pursue non-redistributing, pro-labour policies. The estimated coefficients may be unbiased if all governments pursue growth maximizing, or redistributing policies and $\mathfrak{p}_{i}$ is uncorrelated with $\alpha_{i}$. 
Barro (1991), Table IV, reports that the estimated coefficient for $\mathfrak{q}$ was 0.014 (0.636) and that for $\mathfrak{p}$ was 0.13 (1.3) for regressions that included many variables. When also including the significantly positive variable $i / y$ the estimated coefficient for $\mathfrak{p}$ became negative and was $-0.015(-0.126)$.

Barro (1990), p. S124, interprets the estimated coefficient for $\mathfrak{q}$ as corroboration of his hypothesis that 'the typical country comes close to the quantity of public investment that maximizes the growth rate.' As violations of the standard assumptions for hypothesis testing make such an argument invalid, Proposition 3 provides one reason why such a hypothesis may rest on shaky ground. As any measured positive point estimate of the effect of $\mathfrak{q}$ on growth may be underestimated, it is likely that the ratio of public to total investment positively affects growth, even if all governments pursue growth maximizing policies.

For a sample with heterogeneous policies and a 'true' estimate that is likely to be significantly positive, a hypothesis compatible with the proposition should be that, given everything else, a typical country that increases public investment is likely to increase the growth rate, no matter what policy is pursued. ${ }^{19}$ Given the downward biases for the measured effects of $\mathfrak{q}$ on growth one is led to conclude that an increase in $\mathfrak{q}$ raises growth.

Barro interprets the statistically insignificant, but negative coefficient on $\mathfrak{p}$, when the variable $i / y$ is controlled for, as an indication that 'there is no separate effect on growth from the breakdown of total investment between private and public components'. That suggests the hypothesis that an optimizing public sector invests according to the same criteria as the private sector does. For instance, the public sector may wish to maximize the social return on its investment, just

\footnotetext{
${ }^{19}$ Notice that a significantly positive coefficient does not entail that it should be growth maximizing to push $\mathfrak{q}$ up to 1 when tax base or collection constraints curtail such choices. Those and other provisos are meant by 'given everything else'.
} 
as private sector investors wish to maximize the private return on their investments. Barro implicitly assumes that maximization of the social return on public investment also maximizes the growth rate.

First of all, it is worth noting that under the assumption of exogenous policy the estimated coefficients for the effect of $\mathfrak{p}$ on growth are biased downwards, which suggests that the 'true' effect of public investment may be significantly positive. Under the assumption of endogenous policy the estimated coefficients for the effect of $\mathfrak{p}$ would be biased downwards if the sample contained non-redistributing, pro-labour governments.

Secondly, under the assumption of endogenous policy the negative point estimate suggests that the breakdown matters. A reported value of -0.015 for the effect of $\mathfrak{p}$ on growth means that holding total investment constant and raising public investment with a compensating cut in private investment reduces growth. Thus, a negative point estimate in that regression implies that a typical country's policy which crowds out private (steady state) investment is bad for growth. That implication may be a valid result (unbiased estimates) for samples where, according to Proposition 3, all countries are led by growth maximizing, or redistributing, pro-labour policies and $\operatorname{cov}\left(\mathfrak{p}, \alpha_{i}\right)=0$. But given unbiasedness and statistical insignificance, it follows that other than growth maximizing policies would also lead to no crowding out of public and private investment. That, in turn, implies that a statistically insignificant value does not mean that governments have maximized the social return on public investment. Thus, other welfare objectives are compatible with an insignificant coefficient.

Barro views his empirical results as 'ongoing research' and is aware of the econometric problems mentioned above. However, he does not investigate the implications of endogenous policy. Here it follows that under endogenous policy 
the estimated coefficients for the effect on growth of the ratio of public investment to total investment are generally biased downwards. The estimated coefficients for the effect on growth of the ratio of public investment to GDP may be unbiased if that ratio is uncorrelated with the share of capital and other than nonredistributing, pro-labour policies are pursued. Otherwise, there is a downward bias in the estimated coefficients.

Interestingly, if one assumes exogenous policy, the coefficients measuring the effect of that variable on growth are definitely biased downwards. Hence, reported insignificant negative point estimates for that coefficient in simple cross-country OLS regressions may be either biased downwards and so the 'true' coefficient may really be significantly positive or they are unbiased, but provide no corroboration of the hypothesis that all countries are lead by growth maximizing policies.

Redistributive Transfers. Some researchers test the effect of redistributive transfers such as social benefits, social security contributions etc. on growth. Transfers of that kind are political instruments to correct for socially unwanted pre-tax income inequality. In that context growth is often regressed on the ratio of redistributive transfers to GDP, which - in this model - is given by ${ }^{20}$

$$
\mathfrak{b} \equiv \frac{\lambda \tau K_{t}}{Y_{t}}=\frac{\lambda \tau K_{t}}{A K_{t}^{\alpha} G_{t}^{1-\alpha}}=\frac{\tau K_{t}\left(\frac{G_{t}}{K_{t}}\right)^{\alpha}}{A G_{t}}=\frac{\lambda((1-\lambda) \tau)^{\alpha}}{A(1-\lambda)}
$$

where $\tau=\rho$ from $(10), G_{t}=(1-\lambda) \tau K_{t}$ and by assumption some governments in the sample choose $\lambda>0$ so that data on redistribution are actually available. Then a regression of $\gamma$ on $\mathfrak{b}$ produces biased estimates for the following reasoning:

Firstly, for given policy and $\operatorname{cov}\left(\mathfrak{b}_{i}, \alpha_{i}\right) \leq 0$, the estimated effect of $\mathfrak{b}$ on

\footnotetext{
${ }^{20}$ Table 1 implies that a regression of the growth rate on the ratio of transfers to tax revenues, that is, $\lambda$ would also yield coefficients that are biased downwards.
} 
growth are biased downwards. Secondly, under the assumption of endogenous policy Table 1 implies that $\frac{d \mathfrak{b}}{d \alpha}$ and so $\operatorname{cov}\left(\mathfrak{b}_{i}, \alpha_{i}\right)$ are ambiguous in sign. Then $\frac{d \mathfrak{b}}{d A}=\mathfrak{b}_{\lambda} \frac{d \lambda}{d A}+\lambda_{A}<0$ since $\lambda_{A}<0, \mathfrak{b}_{\lambda}>0, \frac{d \lambda}{d A}<0$ and $\tau=\rho$ which is independent of $A$, suggesting that simple OLS estimates for the effect of $\mathfrak{b}_{i}$ on $\gamma_{i}$ are biased downwards, that is, if $\operatorname{cov}\left(\mathfrak{b}_{\mathfrak{i}}, \alpha_{i}\right) \leq 0$ in the sample or the covariance is less important than that of $\operatorname{cov}\left(\mathfrak{b}_{i}, A_{i}\right)$ the estimated effect of transfers on growth are biased downwards.

Proposition 4 If $\operatorname{cov}\left(\mathfrak{b}_{i}, \alpha_{i}\right) \leq 0$ and some countries in the sample are led by redistributing governments the model predicts that in simple cross-country OLS regressions the estimates measuring the effect on growth of the ratio of redistributive transfers to GDP are biased downwards.

Hence, any reported bad effect of redistributive transfers is overstated and any reported good effect is understated. The downward bias would even be present if one assumed that policy is exogenous. Many theoretical models show that redistributive transfers are bad for growth. The reason for overstating any measured negative effect of redistributive transfers on growth in this model is due to the prediction that countries with more efficient economies and redistributing governments choose to redistribute less resources per units of taxes collected.

As Proposition 4 does not say anything on the magnitude of the bias, the latter may be as large as minus infinity. That means, the hypothesis that redistributive transfers are bad for growth cannot be validated by any reported negative coefficient on transfers in simple OLS growth regressions. Thus, for simple OLS growth regressions Proposition 4 would render the hypothesis generically untestable.

In fact, these arguments suggest the opposite hypothesis, namely that redis- 
tributive transfers affect growth in a positive way. For instance, Perotti (1994) is surprised to find a significantly positive coefficient on redistributive transfers in his regressions of investment on policy variables. He quotes other studies that have found a positive relation between transfers and growth. (See ftn. 8 of his paper.) Sala-i-Martin (1996) states that it is surprising that among the three components of public spending - public investment, public consumption and public transfers - the only one that seems to be positively related to growth is the redistributive transfer variable. For instance, social security contributions are often found to affect growth in a positive way.

In that sense Proposition 4 explains why one may get positive coefficients on redistributive transfer variables in simple OLS cross-country growth regressions under the hypothesis that redistribution is bad for growth. Of course, the proposition is perfectly compatible with the hypothesis that redistributive transfers positively affect growth.

\section{Conclusion}

Within a common theoretical framework it is shown how optimizing governments take account of fundamental economic variables when making their decisions so that public policy is economically endogenous and has interesting effects on longrun growth. Several findings of the paper are noteworthy.

First, under certain conditions the policies optimal for the accumulated factor of production (growth maximization) may also be pursued if a government has other welfare objectives. An increase in technological efficiency generally raises optimal taxes and growth under the policies considered.

Second, when policy is endogenous the estimated coefficients on policy vari- 
ables are generically biased. The direction of the biases are deduced from the theoretical model, providing some explanations for certain, sometimes puzzling point estimates found in the empirical literature.

Third, it is shown that the effects on growth of some widely used variables such as tax rate variables related to GDP, the ratio of public investment to total investment and the ratio of redistributive transfers to GDP are generally biased downwards.

For instance, for the latter this implies the following: Under the assumption that policy is economically endogenous, the effect of redistributive transfer variables on growth are generally underestimated so that the hypothesis that redistribution is bad for growth may not be testable. The downward bias is, however, perfectly consistent with empirical findings in the literature which find a positive association between redistributive transfers and growth. It may also represent corroboration of the hypothesis that redistribution is not bad for growth.

The paper argues that more work is needed for the disentanglement of the interplay of long-run economic fundamentals - like social fabrics, technology, history, institutions, or geography - and policy on the one hand, and policy and growth on the other. 


\section{A The capitalists' optimum}

The current value Hamiltonian for the problem (5) - (7) is given by

$$
H=\ln C_{t}^{k}+\mu_{t}\left((r-\tau) K_{t}-C_{t}^{k}\right) .
$$

The necessary first order conditions for its maximization are given by (6), (7) and

$$
\begin{gathered}
\frac{1}{C_{t}^{k}}-\mu_{t}=0 \\
\dot{\mu_{t}}=\mu_{t} \rho-\mu_{t}(r-\tau) \\
\lim _{t \rightarrow \infty} K_{t} \mu_{t} e^{-\rho t}=0,
\end{gathered}
$$

where the positive co-state variable $\mu_{t}$ represents the instantaneous shadow price of one more unit of investment at date $t$.

From (A2a) and (A2b) consumption grows at $\gamma \equiv \frac{\dot{C}_{t}^{k}}{C_{t}^{k}}=R-\rho$ where $R \equiv(r-\tau)$ and constant. Thus, $C_{t}=C_{0} e^{(R-\rho) t}$ where $C_{0}$ remains to be determined. Substituting for $C_{t}$ in (6) implies $\dot{K}_{t}=R K_{t}-C_{0} e^{(R-\rho) t}$ which is a first order, linear differential equation in $K_{t}$ and solved as follows

$$
\begin{aligned}
\dot{K}_{t}-R K_{t} & =-C_{0} e^{\gamma t} \\
e^{-R t}\left(\dot{K}_{t}-R K_{t}\right) & =-e^{-R t} C_{0} e^{\gamma t} \\
\int e^{-R t}\left(\dot{K}_{t}-R K_{t}\right) d t & =-\int C_{0} e^{-\rho t} d t
\end{aligned}
$$

The last equation is an exact differential equation with integrating factor $e^{-R t}$. The LHS is solved by $K_{t} e^{-R t}+b_{0}$ and the RHS is solved by $\frac{C_{0}}{\rho} e^{-\rho t}+b_{1}$, where $b_{0}, b_{1}$ are arbitrary constants. Thus, $K_{t}=\frac{C_{0}}{\rho} e^{(R-\rho) t}+b e^{R t}$ where $b=b_{1}-b_{0}$. Substituting this into the transversality condition implies

$$
\frac{1}{C_{0}} \lim _{t \rightarrow \infty}\left(\frac{C_{0}}{\rho} e^{(R-\rho) t}+b e^{R t}\right) e^{-R t}=\lim _{t \rightarrow \infty}\left(\frac{1}{\rho} e^{-\rho t}+\frac{b}{C_{0}}\right)=0
$$

which holds if the arbitrary constant $b$ is set equal to zero. Then $K_{t}=\frac{C_{0}}{\rho} e^{\gamma t} \Rightarrow \gamma_{k}=$ $\gamma=R-\rho$ so that consumption and wealth grow at the same constant rate in the optimum. Furthermore, the optimal level of consumption at each date is given by $C_{t}=\rho K_{t}$. 


\section{B Welfare}

The agents' welfare is $V\left(C^{j}\right)=\int_{0}^{t} \ln C_{t}^{j} e^{-\rho t}$ where $j=k, W$. Let $t \rightarrow \infty$ and use integration by parts. For this define $v_{2}=\ln C_{t}^{j}$, and $d v_{1}=e^{-\rho t} d t$. Recall $d v_{2}=\frac{\dot{C}_{t}^{j}}{C_{t}^{j}}=\gamma$ and constant. Then $v_{1}=-\frac{1}{\rho} e^{-\rho t}$ so that

$$
\begin{aligned}
\int_{0}^{\infty} \ln C_{t}^{j} e^{-\rho t} d t & =\frac{1}{\rho}\left[-\ln C_{t}^{j} e^{-\rho t}\right]_{0}^{\infty}+\frac{1}{\rho} \int_{0}^{\infty} \gamma e^{-\rho t} d t \\
& =\frac{\ln C_{0}^{j}}{\rho}-\frac{1}{\rho^{2}}\left[\gamma e^{-\rho t}\right]_{0}^{\infty}
\end{aligned}
$$

where $C_{0}^{k}=\rho K_{0}$ and $C_{0}^{W}=(\eta+\lambda \tau) K_{0}$. Evaluation at the particular limits yields the expressions in (9).

\section{Optimal Policies}

The government solves: $\max _{\tau, \lambda}(1-\beta) V^{r}+\beta V^{l}$ s.t. $\lambda \geq 0$ where $\beta$ is the social weight attached to the workers' welfare. The FOCs are

$$
\beta \frac{\eta_{\tau}+\lambda}{(\eta+\lambda \tau) \rho}+\frac{\gamma_{\tau}}{\rho^{2}}=0 \quad, \quad \lambda\left(\beta \frac{\eta_{\lambda}+\tau}{(\eta+\lambda \tau) \rho}+\frac{\gamma_{\lambda}}{\rho^{2}}\right)=0
$$

Notice that $\gamma_{\tau}$ must be negative for the first equation to hold, so in the optimum $\tau>\hat{\tau}$. Concentrating on an interior solution for $\lambda$, simplifying, rearranging and division of the resulting two equations by one another yields

$$
\frac{\eta_{\tau}+\lambda}{\eta_{\lambda}+\tau}=\frac{\gamma_{\tau}}{\gamma_{\lambda}}
$$

Then $\gamma_{\lambda}=r_{\lambda}$ and $\gamma_{\tau}=r_{\tau}-1$ imply $\left(\eta_{\tau}+\lambda\right) r_{\lambda}=\left(\eta_{\lambda}+\tau\right)\left(r_{\tau}-1\right)$ which upon multiplying out becomes $\eta_{\tau} r_{\lambda}+\lambda r_{\lambda}=r_{\tau} \eta_{\lambda}+r_{\tau} \tau-\eta_{\lambda}-\tau$. Notice $r_{\lambda} \eta_{\tau}=r_{\tau} \eta_{\lambda}$ and $\eta=\frac{1-\alpha}{\alpha} r$. Then $\lambda r_{\lambda}=r_{\tau} \tau-\frac{1-\alpha}{\alpha} r_{\lambda}-\tau$ and so

$$
\left(\lambda+\frac{1-\alpha}{\alpha}\right) r_{\lambda}=\tau r_{\tau}-\tau \Leftrightarrow\left(\lambda+\frac{1-\alpha}{\alpha}\right)=\frac{\tau r_{\tau}}{r_{\lambda}}-\frac{\tau}{r_{\lambda}} .
$$

Recall $r_{\tau}=\alpha E(1-\lambda), r_{\lambda}=\alpha E(-\tau)$ where $E=(1-\alpha) A[(1-\lambda) \tau]^{-\alpha}$. Thus, $\frac{\tau r_{\tau}}{r_{\lambda}}=$ $-\frac{\tau \alpha E(1-\lambda)}{\alpha E \tau}=-(1-\lambda)$ and $\lambda+(1-\lambda)+\frac{1-\alpha}{\alpha}=-\frac{\tau}{r_{\lambda}} \Leftrightarrow \frac{r_{\lambda}}{\alpha}=-\tau$ and so

$$
\tau=\frac{[(1-\alpha) A]^{\frac{1}{\alpha}}}{1-\lambda}
$$


Notice that for this $\tau$ we have $E=1$. For the first order condition for $\tau$ we note that $\eta=(1-\alpha) A[(1-\lambda) \tau]^{1-\alpha}=E[(1-\lambda) \tau]=[(1-\alpha) A]^{\frac{1}{\alpha}}$. Furthermore, $\eta_{\tau}=$ $(1-\alpha)(1-\lambda), r_{\tau}=\alpha(1-\lambda)$. Eqn. (C2) implies $\lambda=1-\frac{[(1-\alpha) A]^{\frac{1}{\alpha}}}{\tau}$ so that

$$
\eta+\lambda \tau=[(1-\alpha) A]^{\frac{1}{\alpha}}+\tau\left(1-\frac{[(1-\alpha) A]^{\frac{1}{\alpha}}}{\tau}\right)=\tau .
$$

Then the first order condition for $\tau$ becomes

$$
\beta \frac{\eta_{\tau}+\lambda}{(\eta+\lambda \tau)}=-\frac{\gamma_{\tau}}{\rho} \quad \Leftrightarrow \quad \frac{\eta_{\tau}+\lambda}{\tau}=-\frac{\gamma_{\tau}}{\beta \rho} \quad \Leftrightarrow \quad \frac{\eta_{\tau}+\lambda}{\gamma_{\tau}}=-\frac{\tau}{\beta \rho} .
$$

But from above $\frac{\eta_{\tau}+\lambda}{\gamma_{\tau}}=\frac{(1-\alpha)(1-\lambda)+\lambda}{\alpha(1-\lambda)-1}=-1$ so that $\tau=\beta \rho$. Thus,

$$
\tau=\beta \rho \quad \text { and } \quad \lambda=1-\frac{[(1-\alpha) A]^{\frac{1}{\alpha}}}{\beta \rho} .
$$

which is equation (10) when $\beta=1$. Recall that these equations hold for $\lambda \geq 0$, thus for $\beta \rho \geq[(1-\alpha) A]^{\frac{1}{\alpha}}$.

Suppose $\lambda=0$, then the first order condition becomes

$$
\frac{\eta_{\tau}}{\eta}=-\frac{r_{\tau}-1}{\beta \rho} \Leftrightarrow \frac{(1-\alpha) E}{\tau E}=-\frac{\alpha E-1}{\beta \rho} \Leftrightarrow(1-\alpha) \beta \rho=\tau-\alpha \tau E
$$

so that the solution with $\lambda=0$ is given by

$$
(1-\alpha) \beta \rho=\tau\left[1-\alpha(1-\alpha) A \tau^{-\alpha}\right]
$$

which holds only if $\beta \rho<[(1-\alpha) A]^{\frac{1}{\alpha}}$. For $\beta=1$ this is equation (11) in the text.

If $\beta=0$, then $\tau=\hat{\tau}$. Thus, the pro-capital policy maximizes growth.

\section{Reactions under Endogenous Policy}

Pro-Capital. $\hat{\gamma}=\frac{\alpha \hat{\tau}}{1-\alpha}-\rho$ and $\hat{\tau}=[\alpha(1-\alpha) A]^{\frac{1}{\alpha}}$. Clearly, $\frac{d \hat{\tau}}{d A}>0$ and $\frac{d \hat{\gamma}}{d A}>0$. Furthermore,

$$
\begin{aligned}
\frac{d \hat{\tau}}{d \alpha} & =\frac{[\alpha(1-\alpha) A]^{\frac{1}{\alpha}-1}(1-2 \alpha) A}{\alpha}-\frac{[\alpha(1-\alpha) A]^{\frac{1}{\alpha}} \ln [\alpha(1-\alpha) A]}{\alpha^{2}} \\
& =\frac{\hat{\tau}(1-2 \alpha)}{\alpha^{2}(1-\alpha)}-\frac{\hat{\tau} \ln \hat{\tau}}{\alpha}
\end{aligned}
$$


which is not easy to evaluate. However, the following plot establishes that $\frac{d \hat{\tau}}{d \alpha} \gtreqless 0$ for a particular level of $A$.

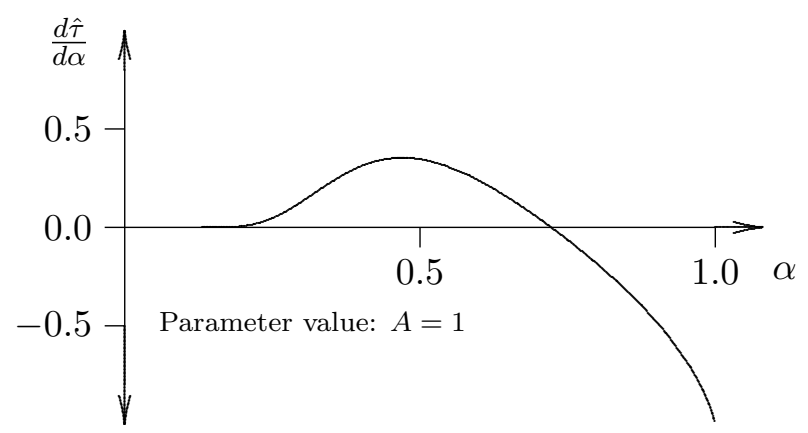

Thus, for two different values of the share of capital one may have the same $\hat{\tau}$. As $\frac{d \hat{\tau}}{d \alpha} \gtreqless 0$ the sign of $\frac{d \hat{\gamma}}{d \alpha}$ is not clear. For the calculation of $\frac{d \hat{\gamma}}{d \alpha}$ rearrange to get $(\hat{\gamma}+\rho)=\frac{\alpha \hat{\tau}}{1-\alpha}$. Then

$$
\begin{aligned}
\ln (\hat{\gamma}+\rho) & =\ln \alpha-\ln (1-\alpha)+\ln \hat{\tau} \\
& =\ln \alpha-\ln (1-\alpha)+\frac{\ln (\alpha(1-\alpha) A)}{\alpha} \\
& =\left(\frac{\alpha+1}{\alpha}\right) \ln \alpha+\left(\frac{1-\alpha}{\alpha}\right) \ln (1-\alpha)+\left(\frac{1}{\alpha}\right) \ln A
\end{aligned}
$$

For the effect of a change in $\alpha$ on this expression one gets

$$
\begin{aligned}
\frac{d \ln (\hat{\gamma}+\rho)}{d \alpha} & =-\left(\frac{1}{\alpha^{2}}\right) \ln \alpha+\left(\frac{\alpha+1}{\alpha^{2}}\right)-\left(\frac{1}{\alpha^{2}}\right) \ln (1-\alpha)-\frac{1}{\alpha}-\left(\frac{1}{\alpha^{2}}\right) \ln A \\
& =\frac{1}{\alpha}\left[\frac{1}{\alpha}-\left(\frac{1}{\alpha}\right) \ln (\alpha(1-\alpha) A)\right]=\frac{1}{\alpha}\left[\frac{1}{\alpha}-\ln \hat{\tau}\right] .
\end{aligned}
$$

As $\hat{\tau}<1$ the expression is positive. Then $\frac{d \ln (\hat{\gamma}+\rho)}{d \alpha}>0$ which implies $\frac{d \hat{\gamma}}{d \alpha}>0$.

Redistributing, Pro-Labour. By equation (10) $\check{\tau}=\rho$ so that $\frac{d \check{\tau}}{d \alpha}=0=\frac{d \check{\tau}}{d A}$. As $\lambda=1-\frac{[(1-\alpha) A]^{\frac{1}{\alpha}}}{\rho}$ it follows that $\frac{d \lambda}{d A}<0$. Next, let $c \equiv(1-\alpha) A$, then

$$
\frac{d \lambda}{d \alpha}=-\frac{1}{\rho}\left[-\frac{A c^{\frac{1-\alpha}{\alpha}}}{\alpha}-\frac{c^{\frac{1}{\alpha}} \ln c}{\alpha^{2}}\right]=\frac{c^{\frac{1}{\alpha}}}{\alpha \rho}\left[\frac{1}{1-\alpha}+\frac{\ln (1-\alpha)+\ln A}{\alpha}\right] .
$$

Suppose $A$ is low (e.g. $A<e^{-\frac{\alpha}{1-\alpha}}$ ), then $\frac{d \lambda}{d \alpha}<0$. Next, suppose $c \approx 1$, then $\frac{d \lambda}{d \alpha}>0$. Thus, the sign of $\frac{d \lambda}{d \alpha}$ is ambiguous.

From equation $(10) r=\alpha A[(1-\lambda) \tau]^{1-\alpha}=\frac{\alpha}{1-\alpha}[(1-\alpha) A]^{\frac{1}{\alpha}}$ so that $\frac{d \check{\gamma}}{d A}>0$ under 
that policy. Furthermore, rearrangement yields

$$
\ln (\gamma+2 \rho)=\ln \alpha+\frac{1-\alpha}{\alpha} \ln (1-\alpha)+\frac{1}{\alpha} \ln A
$$

Taking the derivative yields

$$
\frac{d \ln (\gamma+2 \rho)}{d \alpha}=\frac{1}{\alpha}-\frac{1}{\alpha^{2}} \ln [(1-\alpha) A]-\frac{(1-\alpha)}{\alpha(1-\alpha)}
$$

which is positive since $(1-\alpha) A=(1-\lambda) \tau<1$ in (10). Hence, $\frac{d \check{\gamma}}{d \alpha}>0$.

Non-Redistributing, Pro-Labour. For $\lambda=0$ the optimal tax rate $\check{\tau}$ solves equation (11), that is, $z=\frac{\tau}{1-\alpha}-\alpha A \tau^{1-\alpha}-\rho=0$. The partial derivatives of $z$ are given by

$$
z_{\tau}=\frac{1}{1-\alpha}-(1-\alpha) \alpha A \tau^{-\alpha} \text { and } \quad z_{\alpha}=\frac{\tau}{(1-\alpha)^{2}}-A \tau^{1-\alpha}+\alpha A \tau^{1-\alpha} \ln \tau
$$

with $z_{\tau}$ being positive for all $\tau>\hat{\tau}$. As $z_{A}<0$ it follows that $\frac{d \check{\tau}}{d A}=-\frac{z_{A}}{z_{\tau}}>0$ under that policy. Furthermore,

$$
\begin{aligned}
\frac{d \tau}{d \alpha}=-\frac{z_{\alpha}}{z_{\tau}} & =-\frac{\frac{\tau}{(1-\alpha)}-(1-\alpha) A \tau^{1-\alpha}+\alpha(1-\alpha) A \tau^{1-\alpha} \ln \tau}{1-(1-\alpha)^{2} \alpha A \tau^{-\alpha}} \\
& =\frac{\tau\left[-\frac{1}{(1-\alpha)}+(1-\alpha) A \tau^{-\alpha}-\alpha(1-\alpha) A \tau^{-\alpha} \ln \tau\right]}{1-(1-\alpha)^{2} \alpha A \tau^{-\alpha}}
\end{aligned}
$$

where the first term in $z_{\alpha}$ is positive, but the sum of the other two terms is negative. However, $\check{\tau} \in\left((\alpha(1-\alpha) A)^{\frac{1}{\alpha}},((1-\alpha) A)^{\frac{1}{\alpha}}\right)$. Suppose $\check{\tau} \rightarrow(\alpha(1-\alpha) A)^{\frac{1}{\alpha}}$ and $A=1$. Then the $\frac{d \tau}{d \alpha}$ reduces to

$$
\frac{\hat{\tau}(1-2 \alpha)}{\alpha^{2}(1-\alpha)}-\frac{\hat{\tau} \ln \hat{\tau}}{\alpha}
$$

which is the same expression as that for $\frac{d \hat{\tau}}{d \alpha}$ in (D1). Hence, $\frac{d \check{\tau}}{d \alpha} \gtreqless 0$.

For the growth rate one finds $\frac{d \gamma}{d A}=r_{A}+\left(r_{\tau}-1\right) \frac{d \tau}{d A}>0$ if

$$
\begin{aligned}
\alpha \tau^{1-\alpha} & >\left(1-\alpha(1-\alpha) A \tau^{-\alpha}\right)\left[\alpha(1-\alpha) \tau\left(\tau^{\alpha}-\alpha(1-\alpha)^{2} A\right)^{-1}\right] \\
\tau^{\alpha}-\alpha^{2}(1-\alpha)^{2} A & >(1-\alpha) \tau^{\alpha}-\alpha^{2}(1-\alpha)^{2} A
\end{aligned}
$$


which is equivalent to $1>1-\alpha$ and true. Thus, $\frac{d \check{\gamma}}{d A}>0$ if $\lambda=0$ in (11). Furthermore,

$$
\begin{aligned}
\frac{d \check{\gamma}}{d \alpha} & =A \tau^{1-\alpha}-\frac{d \tau}{d \alpha}-\alpha A\left[\tau^{1-\alpha} \ln \tau\right]+\alpha(1-\alpha) A \tau^{-\alpha} \frac{d \tau}{d \alpha} \\
& =A \tau^{1-\alpha}-\alpha A\left[\tau^{1-\alpha} \ln \tau\right]-\left[1-\alpha(1-\alpha) A \tau^{-\alpha}\right] \frac{d \tau}{d \alpha}
\end{aligned}
$$

I want to show that $\frac{d \check{\gamma}}{d \alpha}>0$ for any $\check{\tau} \in\left((\alpha(1-\alpha) A)^{\frac{1}{\alpha}},((1-\alpha) A)^{\frac{1}{\alpha}}\right)$. For that it suffices to show that $\frac{d \tau}{d \alpha}<A \tau^{1-\alpha}$, since $-\alpha A\left[\tau^{1-\alpha} \ln \tau\right]$ is non-negative. For the rest of the proof it is convenient to represent the solution space $\check{\tau}$ in the form

$$
\check{\tau}=x((1-\alpha) A)^{\frac{1}{\alpha}} \quad \text { where } x \in\left(\alpha^{\frac{1}{\alpha}}, 1\right) \Leftrightarrow \quad \check{\tau} \in\left((\alpha(1-\alpha) A)^{\frac{1}{\alpha}},((1-\alpha) A)^{\frac{1}{\alpha}}\right) .
$$

Higher $x$ implies a higher optimal $\check{\tau}$. I want to show that $\frac{d \tau}{d \alpha}<A \tau^{1-\alpha}$, that is,

$$
\begin{gathered}
\frac{\frac{\tau}{(1-\alpha)}-(1-\alpha) A \tau^{1-\alpha}+\alpha(1-\alpha) A \tau^{1-\alpha} \ln \tau}{1-(1-\alpha)^{2} \alpha A \tau^{-\alpha}}<A \tau^{1-\alpha} \\
\frac{\tau^{\alpha}}{A(1-\alpha)^{2}}-1+\alpha \ln \tau<\frac{1}{1-\alpha}-\alpha(1-\alpha) A \tau^{-\alpha}
\end{gathered}
$$

Substituting $\check{\tau}$ for $\tau$ yields

$$
\begin{aligned}
\frac{x^{\alpha}}{1-\alpha}-1+\alpha \ln \check{\tau} & <\frac{1}{1-\alpha}-\frac{\alpha}{x^{\alpha}} \\
\frac{\alpha}{x^{\alpha}}-1+\alpha \ln \check{\tau} & <\frac{1-x^{\alpha}}{1-\alpha}
\end{aligned}
$$

and holds since $\alpha \ln \check{\tau}$ is unambiguously negative, $\frac{\alpha}{x^{\alpha}}<1$ and $x^{\alpha}>1$ for all $x \in\left(\alpha^{\frac{1}{\alpha}}, 1\right)$. Hence, $\frac{d \check{\gamma}}{d \alpha}>0$. 


\section{References}

Alesina, A. and D. Rodrik, "Distributive Politics and Economic Growth," Quarterly Journal of Economics, 1994, 109, 465-490.

Aschauer, D. A., "Is Public Expenditure Productive?," Journal of Monetary Economics, 1989, 23, 177-200.

Banerjee, A., M. Marcellino, and C. Osbat, "Some Cautions on the Use of Panel Methods for Integrated Series of Macro-Economic Data," Working Paper 170, IGIER, Bocconi University, Milano 2000.

Barro, R. J., "A Cross-Country Study of Growth, Saving, and Government," Working Paper 2855, NBER 1989.

, "Economic Growth in a Cross Section of Countries," Working Paper 3120, NBER 1989.

, "Government Spending in a Simple Model of Endogenous Growth," Journal of Political Economy, 1990, 98, S103-S125.

"Economic Growth in a Cross Section of Countries," Quarterly Journal of Economics, 1991, 106, 407-444.

_ Determinants of Economic Growth: A Cross-Country Empirical Study, Cambridge, Mass.: MIT Press, 1997.

and X. Sala-i-Martin, "Public Finance in Models of Economic Growth," Review of Economic Studies, 1992, 59, 645-661.

and __ Economic Growth, New York: McGraw-Hill, 1995.

Bertola, G., "Factor Shares and Savings in Endogenous Growth," American Economic Review, 1993, 83, 1184-1198.

Bourguignon, F., "Pareto Superiority of Unegalitarian Equilibria in Stiglitz' Model of Wealth Distribution with Convex Saving Function," Econometrica, 1981, 49, 1469-1475.

Caselli, F., G. Esquivel, and F. Lefort, "Reopening the Convergence Debate: A New Look at Cross-Country Growth Empirics," Journal of Economic Growth, 1996, 1, 363-389.

Easterly, W. and S. Rebelo, "Fiscal policy and economic growth. An empirical investigation," Journal of Monetary Economics, 1993, 32, 417-458.

_ and ___ "Marginal Income Tax Rates and Economic Growth in Developing Countries," European Economic Review, 1993, 37, 409-417.

Engen, E. M. and J. Skinner, "Fiscal Policy and Economic Growth," Working Paper 4223, NBER 1992.

Engle, R. F., D. F. Hendry, and J.-F. Richard, "Exogeneity," Econometrica, 1983, 51, $277-304$

Jones, L. E., R. E. Manuelli, and P. E. Rossi, "Optimal Taxation in Models of Endogenous Growth," Journal of Political Economy, 1993, 101, 485-517.

Kaldor, N., "Alternative Theories of Income Distribution," Review of Economic Studies, 1956, $48(5), 83-100$.

King, R. G. and S. Rebelo, "Public Policy and Economic Growth: Developing Neoclassical Implications," Journal of Political Economy, 1990, 98, S126-S150. 
Koester, R. B. and R. C. Kormendi, "Taxation, Aggregate Activity and Economic Growth: Cross-Country Evidence on Supply-Side Hypotheses," Economic Inquiry, 1989, 27, 367386.

Levine, R. and D. Renelt, "A Sensitivity Analysis of Cross-Country Growth Regressions," American Economic Review, 1992, 82, 942-963.

Lucas, R. E., "Supply-Side Economics: An Analytical Review," Oxford Economic Papers, 1990, 42, 293-316.

Mankiw, N. G., D. Romer, and D. N. Weil, "A Contribution to the Empirics of Economic Growth," Quarterly Journal of Economics, 1992, 152, 407-437.

Pasinetti, L., "Rate of Profit and Income Distribution in Relation to the Rate of Economic Growth," Review of Economic Studies, 1962, 29, 267-279.

Pecorino, P., "Tax structure and growth in a model with human capital," Journal of Public Economics, 1993, 52, 251-271.

Perotti, R., "Income distribution and investment," European Economic Review, 1994, 38, $827-835$.

, "Growth, Income Distribution, and Democracy: What the Data Say," Journal of Economic Growth, 1996, 1, 149-187.

Persson, T. and G. Tabellini, "Is Inequality Harmful for Growth?," American Economic Review, 1994, 84, 600-621.

Rebelo, S., "Long-Run Policy Analysis and Long-Run Growth," Journal of Political Economy, 1991, 99, 500-521.

Sala-i-Martin, X., "A Positive Theory of Social Security," Journal of Economic Growth, 1996, 1, 277-304.

__ "I Just Ran Two Million Regressions," American Economic Review, Papers and Proceedings, May 1997, 87, 178-188.

Schlicht, E., "A Neoclassical Theory of Wealth Distribution," Jahrbücher für Nationalökonomie und Statistik, 1975, 189, 78-96.

Spanos, A., Statistical Foundations of Econometric Modelling, Cambridge, UK: Cambridge University Press, 1986.

Stokey, N. L. and S. Rebelo, "Growth Effects of Flat-Rate Taxes," Journal of Political Economy, 1995, 103, 519-550.

Temple, J., "The New Growth Evidence," Journal of Economic Literature, 1999, 37, 112-156. 